\title{
Water Susceptibility and Mechanical Properties of Thermoplastic Starch-Pectin Blends Reactively Extruded with Edible Citric Acid
}

\author{
Alessandra Luzia Da Róz $z^{a *}$, Pricila Veiga-Santos ${ }^{b}$, Adriane Medeiros Ferreira ${ }^{c}$, \\ Thaís Cristina Ribeiro Antunes ${ }^{a}$, Fabio de Lima Leite ${ }^{a}$, Fabio Minoru Yamaji ${ }^{a}$, \\ Antonio José Felix de Carvalho \\ ${ }^{a}$ Federal University of São Carlos - UFSCar, Avenida General Carneiro, 1101, \\ CEP 18043-970, Sorocaba, SP, Brazl \\ ${ }^{b}$ Faculdade de Ciências Agronômicas - FCA, Universidade Estadual Paulista Júlio de Mesquita Filho - UNESP, \\ Avenida Marechal Floriano Peixoto, 240, CEP 18603-970, Botucatu, SP, Brazil \\ ${ }^{c}$ Department of Materials Engineering, University of São Paulo - USP, Rua Episcopal, 1457, \\ CEP 13560-970, São Carlos, SP, Brazil
}

Received: April 10, 2015; Revised: October 7, 2015; Accepted: November 22, 2015

\begin{abstract}
Pectin and starch are edible, non-toxic, biodegradable and obtained from renewable sources. Also have the benefit to be easily cross-linked producing hydrogels. Reactive extrusion with edible citric acid and cross linking interactions was evaluated on extruded thermoplastic in natura and cationic starch-pectin blends. Materials water susceptibility and mechanical properties were characterised. Reactive extrusion decreased (up to $75 \%$ in natura starch) mechanical properties. Also have decreased (up to $32.4 \%$ ) both starch polymers water absorption, indicating the possibility of increasing materials water barrier properties but had the opposite effect on the pectin-TPS material, probably related to a cationic-anionic cross linking, resulting in a hydrogel polymer. Reactive extrusion also have negatively affected mechanical properties of both starch polymers, however increased pectin-TPS blends stress and strain at rupture.
\end{abstract}

Keywords: Extrusion, Bio-based products, Biodegradable packaging, Starch, pectin.

\section{Introduction}

Eco-friendly materials has emerged as one of the most reliable and promising solutions for the food and drug packaging next generation ${ }^{1-3}$. In this context, thermoplastic starch (TPS) ${ }^{4-11}$ and pectin ${ }^{12-15}$ are promising bases for polymers manufacture due to their wide availability, low cost, renewable character and ability of being produced using traditional processing techniques used in the plastics industry, such as extrusion.

TPS and pectin polymer blends have been successfully developed resulting in good mechanical properties and oxygen barrier properties polymers ${ }^{16-21}$, especially regarding high methoxyl pectin. Furthermore, the association between cationic TPS and pectin has also been examined in various studies ${ }^{22,23}$. Cationic starch and high methoxyl pectin may interact favourably with one another due to the cationic nature of TPS and the anionic nature of the high methoxyl pectin. According to Prado and Matulewicks ${ }^{24}$, the combination of cationic polysaccharides with anionic polymers can lead to interpolyeletrolyte complexes (IPECs) with hydrogel like structures, with the possibility of producing a hydrogel physically cross-linked with in natura sources molecules. Such possibility has a great impact in developing food contact polymers, once conventional crosslinking processes usually uses toxic compounds, such as epichlorohydrin ${ }^{24-25}$.

*e-mail: alessandra.roz@gmail.com
Reactive extrusion has been successfully applied to TPS polymers ${ }^{1}$ and has resulted in more flexible and less brittle TPS materials ${ }^{5,26-29}$ when compared to similar TPS materials obtained by conventional extrusion. However, few studies have investigated reative extrusion under edible acids and fewer have examined the use of reactive extrusion on cationic starch bio-based polymers ${ }^{15}$ and even less have studied high methoxyl pectin polymers or pectin-starch composites and neither are information about such polymers mechanical or barrier performance. Cationic and in natura starches were added to pectin in order to evaluate both starches polymers water susceptibility and mechanical properties, when blended by reactive extrusion with pectin in presence of citric acid. Besides of the edible and nontoxic characteristics of citric acid, its utilization is justified also due to pectin ability in forming gel at low $\mathrm{pH}$ (normally using citric acid), in presence of high temperature ${ }^{14-30}$.

\section{Materials and Methods}

\section{Materials}

In natura (not modified) (NM) and cationic (C) corn starch materials were obtained from Unilever Brasil Alimentos Ltda and Corn Products Brazil, respectively. The cationic starch (FH5804) was substitution degree of $0,036 \%$ and an 
ash content of $0,62 \%$, whereas in natura starch containing $28 \%$ amylose and $11 \%$ moisture. Reagent grade CA, glycerol, high methoxyl pectin (GENU type USP-B, CP Kelco Brasil $\mathrm{S} / \mathrm{A}$ ) were used as received. The chemical structures of $\mathrm{CA}$, pectin and $\mathrm{C}$ are provided in Fig. 1.

\section{Processing of thermoplastic starch}

To prepare TPS samples, starch (NM and C), pectin, glycerol $(30 \% \mathrm{wt})$ and $\mathrm{AC}$ were premixed to obtain a homogeneous material (see Table 1 for compositions). The mixtures were processed using a single-screw extruder with an 11-mm screw $(\mathrm{L} / \mathrm{D}=40)$ from AX Plasticos Ltda
(São Paulo, Brazil), with the following zone temperatures from feed to die: $85,110,105$ and $100{ }^{\circ} \mathrm{C}$ at 30 and $27 \mathrm{rpm}$ for the thermoplastic starch, in absence or in presence of the CA, respectively. The processed samples were then hot pressed at $150{ }^{\circ} \mathrm{C}$ into $1 \mathrm{~mm}$ thick plates.

\section{Fourier transform infrared spectroscopy (FTIR)}

Attenuated total reflection (ATR) infrared spectra were recorded on a ThermoScientific Nicolet IR200 spectrophotometer (Rochester, USA). Each spectrum was collected using 64 scans. a)

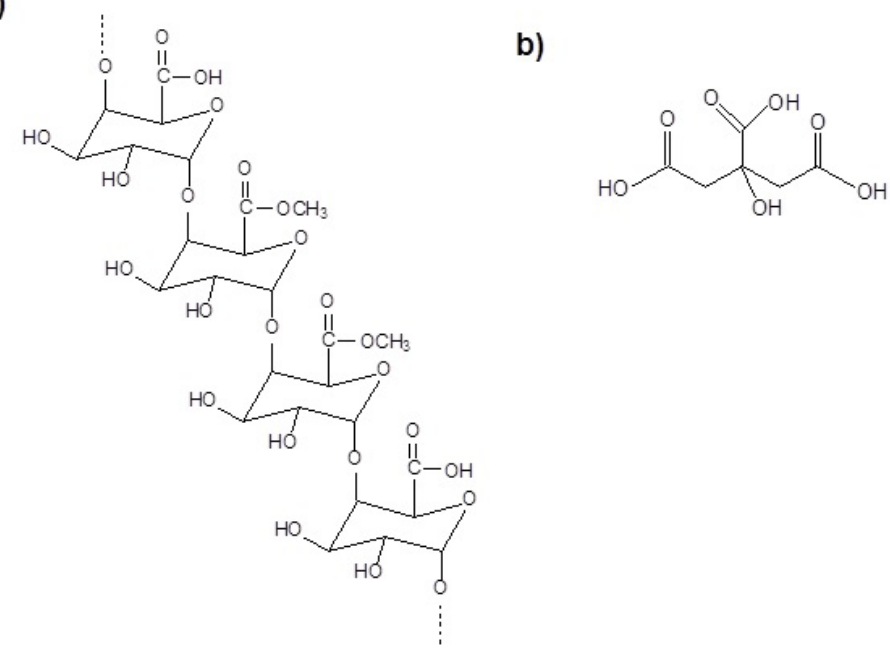

c)

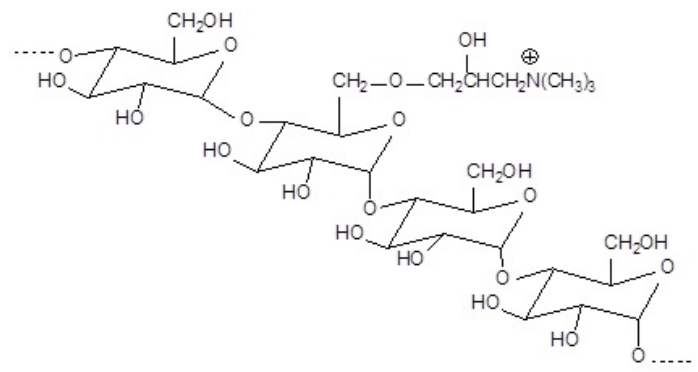

Fig. 1. a) High methoxyl pectin (where $n$ is repetitive unity), b) citric acid (CA) and c) cationic starch structures.

Table 1. Composition and properties of WA and Young's Modulus $(E)$ of polymeric blends.

\begin{tabular}{|c|c|c|c|c|c|c|}
\hline \multirow{2}{*}{$\begin{array}{c}\text { Sample } \\
\text { Identification }\end{array}$} & \multirow{2}{*}{$\begin{array}{l}\text { Starch } \\
\text { Type }\end{array}$} & \multirow{2}{*}{$\mathrm{CA}^{*}(\mathrm{wt} \%)$} & \multirow{2}{*}{ Pectin (wt\%) } & \multirow{2}{*}{$E \mathbf{( M P a}^{+}$} & \multicolumn{2}{|c|}{ WA (\%) } \\
\hline & & & & & $43 \% \mathrm{RH}^{+}$ & $53 \% \mathrm{RH}^{+}$ \\
\hline $\mathrm{A}$ & $\mathrm{N}^{* *}$ & 0.0 & 0.0 & $0.4 \pm 0.005 \mathrm{~A}$ & $9.1 \pm 0.7 \mathrm{C}$ & $13.6 \pm 0.1 \mathrm{H}$ \\
\hline B & $\mathrm{C}^{* * *}$ & 0.0 & 0.0 & $0.4 \pm 0.002 \mathrm{~A}$ & $11.9 \pm 0.6 \mathrm{G}$ & $13.7 \pm 0.5 \mathrm{H}$ \\
\hline $\mathrm{C}$ & $\mathrm{N}$ & 1.5 & 0.0 & $0.1 \pm 0.001 \mathrm{~B}$ & $7.9 \pm 0.4 \mathrm{D}$ & $8.7 \pm 0.2 \mathrm{I}$ \\
\hline $\mathrm{D}$ & $\mathrm{C}$ & 1.5 & 0.0 & -- & -- & -- \\
\hline E & $\mathrm{N}$ & 0.0 & 10.0 & $0.2 \pm 0.04 \mathrm{~B}$ & $14.1 \pm 0.5 \mathrm{E}$ & $18.5 \pm 0.3 \mathrm{~J}$ \\
\hline $\mathrm{F}$ & $\mathrm{C}$ & 0.0 & 10.0 & $0.1 \pm 0.002 \mathrm{~B}$ & $11.6 \pm 0.4 \mathrm{G}$ & $13.9 \pm 0.5 \mathrm{H}$ \\
\hline G & $\mathrm{N}$ & 1.5 & 10.0 & $0.2 \pm 0,007 \mathrm{~B}$ & $11.8 \pm 0.6 \mathrm{~F}$ & $12.5 \pm 0.1 \mathrm{~K}$ \\
\hline $\mathrm{H}$ & $\mathrm{C}$ & 1.5 & 10.0 & $0.1 \pm 0,003 \mathrm{~B}$ & $11.6 \pm 0.3 \mathrm{G}$ & $13.5 \pm 0.6 \mathrm{H}$ \\
\hline I & --- & 0.0 & 100.0 & --- & --- & --- \\
\hline
\end{tabular}

*CA: Citric Acid; $* * \mathrm{~N}$ : in natural (not modified) corn starch; $* * * \mathrm{C}$ cationic corn starch; ${ }^{+}:$letter: Tukey text at $95 \%$ significance 


\section{Dynamic mechanical analysis (DMA)}

DMA measurements were performed on a Q-800 dynamic mechanical analyser (TA Instruments, New Castle, USA) in the tension mode. Measurements were performed at a $25^{\circ} \mathrm{C}$ with a force rate of $0.5 \mathrm{~N} / \mathrm{min}$ under flowing synthetic air. 5 samples each composition, with dimensions of $13 \times 5 \times 1 \mathrm{~mm}$ cut from the hot pressed plates, were tested. Statistical analysis of variance (ANOVA) and Tukey test were performed at 95\% significance level using Tinn-R.

\section{Water absorption (WA)}

Prior to the measurements, the samples were dried at $110 \pm 1{ }^{\circ} \mathrm{C}$ for $12 \mathrm{~h}$ and then placed in containers with relative humidity (RH) values of 43 and $53 \%$ at $25 \pm 2{ }^{\circ} \mathrm{C}$, which were obtained using saturated solutions of $\mathrm{K}_{2} \mathrm{CO}_{3}$ and $\mathrm{Mg}\left(\mathrm{NO}_{3}\right)_{2}$, respectively, as stipulated by ASTM E-104. The amount of water absorbed was measured gravimetrically by weighing the samples until a constant mass was reached (at least 3 samples of each composition were tested and the average values were taken).

\section{Results and Discussion}

Formulations containing both starches in all investigated concentrations were effective in promoting the plasticisation of the blend and resulted in homogeneous materials. The cationic starch samples prepared under reactive extrusion with citric acid CA (sample D) were too sticky to be hot pressed and were not analysed. $100 \%$ pectin samples (sample I) generated a very firm structure during extrusion, and the torque became too high to process it properly. The reactive extrusion of thermoplastic starches in the presence of the CA resulted in a lower viscosity and a higher degree of tackiness, when compared with the material processed in the absence of acids. Such effect may be correlated with the reduction in the molecular mass of starch, indicated by rheological measurements and high performance liquid chromatography ${ }^{5,7}$. Reactive extrusion in presence of CA produced mixtures that were as clear as the TPS samples, whereas the addition of pectin resulted in clear brown samples, because of the pectin natural colour.

The FTIR spectra (Fig. 2) of TPS prepared with cationic and in natura starches (samples A and B) revealed peaks at

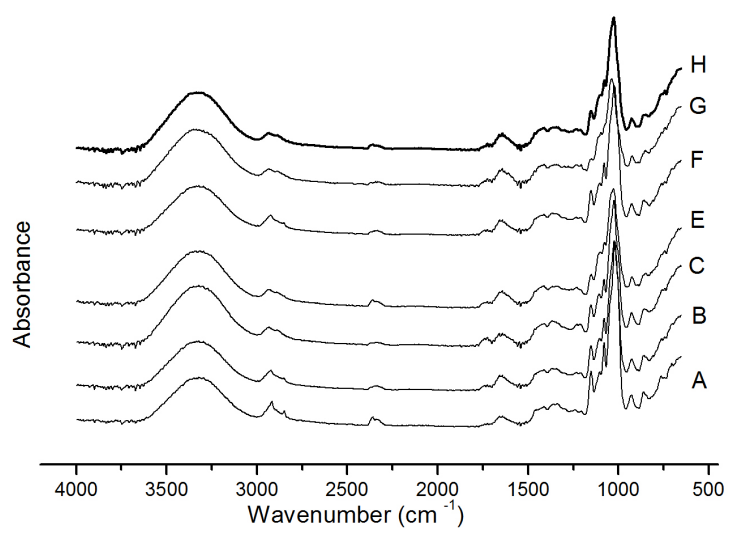

Fig. 2. FTIR spectra of TPS blends.
$3400-3450 \mathrm{~cm}^{-1}$, indicating hydroxyl groups; $2880-2900 \mathrm{~cm}^{-1}$ indicating C-H stretching; and $1150-1085 \mathrm{~cm}^{-1}$, indicating ether ${ }^{31,32}$ presence. Despite some degree of etherification that occurred due to the presence of CA, as observed by Shi et al. ${ }^{33}$, no significant variations $(p<0.05)$ were found in the spectrum of TPS reactive extruded with CA. These results indicate that starch changes observed in this study were most likely related to chain scission ${ }^{5,7}$. The major difference between pectin and starch chemical structure were noted for ester carbonyl groups presence. According to Gnanasambandam, Proctor ${ }^{34}$, the pectin ester carbonyl band area $(\mathrm{C}=\mathrm{O})$ observed at a mean frequency of $1756 \mathrm{~cm}^{-1}$ exhibits the highest correlation with the mean degree of etherification. However, no differences between the samples blended with or without pectin were observed by FTIR in this band region. These results may be explained due to the low percentage of pectin added to the samples prepared in this study.

The kinetics of the water uptake of starch-pectin blends exhibited an asymptotic increase with time until reaching an equilibrium state, which is a characteristic of several hydrophilic bio-based polymers. Samples containing pectin exhibited statistical increased water absorption properties relative the natura TPS (Table 1). This behaviour may be explained by the higher content of $\mathrm{OH}$ groups in the highly methoxylated pectin structures because of its water affinity.

When the in natura starch sample was reactively extruded in the presence of citric acid (sample $\mathrm{C}$ ), a significant $(\mathrm{p}<0.05)$ decrease in the water absorption capacity of the TPS films was observed (Table 1). Such decrease may be explained by a breakage in amylose and amylopectin chains, as discussed by Carvalho et al. ${ }^{5}$; where these chains may become interlaced with other starch chains by intermolecular hydrogen bonding (as opposed to extramolecular hydrogen bonding with water), leading to a lower water uptake capacity. However, in the presence of pectin, all compositions exhibited an increased water uptake. Such results can be explained most likely due to pectin's galacturonic acid hydroxyl, amide and carboxyl groups. Such groups strongly interact with water by macromolecules binding and also by including it in network voids formed in junction zones (gelling). Pectin-water interactions also may be affected by the pectin monovalent cations, as well as by polymer amorphous properties, particle size, surface and porosity ${ }^{35}$.

The higher water absorption capacity of the cationic starch obtained through reactive extrusion compared with that of the in natura starch polymers can be explained by the increase in the number of positive charges due to the cationic starch presence. No statistical difference $(\mathrm{p}<0.05)$ was observed in the cationic starch samples obtained from reactive extrusion with $\mathrm{CA}$ in the presence and absence of pectin, although the sample D was not evaluated (Table 1). This finding suggests that the positive charges in the cationic starch participate in more interactions; thus, the water uptake capacity remained unchanged despite the contribution of additional pectin hydroxyl moieties.

The plots of stress and strain at break are provided in Fig. 3 and Fig. 4, respectively, and the corresponding data for the Young Modulus $(E)$ are summarised in Table 1. The stress-strain plots (not shown) were linear at low strains with high modulus values, which is a characteristic of semi-crystalline 


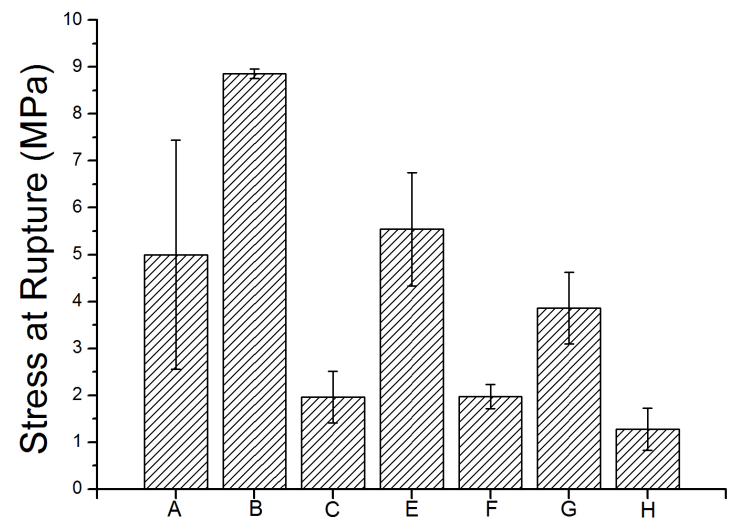

Fig. 3. Stress at rupture values for blends.

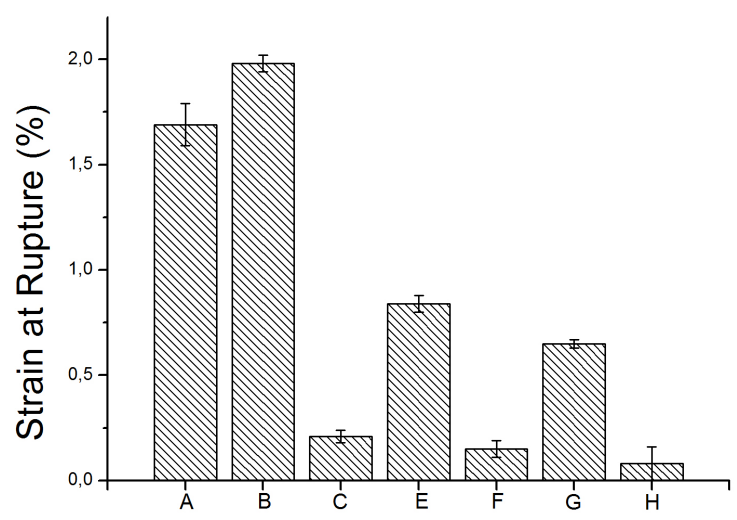

Fig. 4. Strain at rupture values for blends.

materials. TPS starch polymers reactively extruded with CA, in the presence or absence of pectin ( $\mathrm{C}$ and $\mathrm{G}$ samples), did not affected $(p<0.05)$ the materials modulus of elasticity and tension and strain strengths. The addition of pectin, unlike addition of the acid, increased $(p<0.05)$ the water absorption capacity of the films (Table 1) and resulted in a negative effect $(\mathrm{p}<0.05)$ on all the modulus and strain at rupture investigated properties (Table 1). The combination of cationic nature of the starch with the anionic nature of pectin can lead to interpolyeletrolyte complexes (IPECs) with a material hydrogel like structure ${ }^{24,25}$, resulting in

\section{References}

1. Kuorwel KK, Cran MJ, Sonneveld K, Miltz J and Bigger SW. Migration of antimicrobial agents from starch-based films into a food simulant. LWT-Food Science and Technology. 2013; 50(2):432-438.

2. Lopez P, Sanchez C, Batlle R, Nerin C and Lopez P. Development of flexible antimicrobial films using essential oils as active agents. Journal of Agricultural and Food Chemistry. 2007; 55(21):8814-8824.

3. Khalil H, Bhat AH and Yusra AF. Green composites from sustainable cellulose nanofibrils: A review. Carbohydrate Polymers. 2012; 87:963-979. higher hydrophilicity. Such results could be explained due to water plasticizing effect in TPS polymers, which favour intermolecular distance and, consequently, chain mobility. In addition, the pectin polymers may have altered the cationic or in natura TPS polymer matrix interactions due to the presence of the methoxyl groups in pectin, which repelled or hindered bonding between the starch materials, thereby decreasing the mechanical properties of the polymer.

The results observed in this study also demonstrate that reactive extruding in natura or cationic TPS material in the presence of low concentrations of CA (1.5\%) can be an interesting way to alter its properties. Although an improvement in the mechanical properties of TPS materials was observed in a previous study of reactive extrusion ${ }^{5}$, the same results were not observed for the TPS-pectin blends at the concentrations investigated. However, when reactive extrusion was performed on the cationic starch ( $\mathrm{H}$ sample), the resulting materials showed a higher hydrophobic character when compared to the in natura TPS.

\section{Conclusions}

Reactive extrusion with citric acid was used in in natura or cationic starch-pectin blends and all compositions were effective in promoting the plasticisation of the resulted polymer and produced homogeneous blends. When pectin was blended with cationic starch, no change in the water uptake of the resulting materials was observed. In contrast, the reactive blending of pectin with in natura TPS polymers showed a decrease effect on the mechanical properties and water uptake of the blends. Similarly, reactive extrusion of in natura TPS and in natura TPS-pectin blends with CA exhibited materials with lower stress and strain at break and reduced water absorption capacity . Starch and pectin blends produced under reactive extrusion can result in hydrophilic hydrogel polymers with interesting nontoxic and differentiated properties.

\section{Acknowledgements}

This work was supported by CAPES (PNPD 02880/09-1), MCTI/CNPq 407044/2013-2, MEC/MDTI/CAPES/ CNPq/FAPS 117/2012 and FAPESP (JP 2007/08394-7). The authors thank Prof. Dr. Vagner Botaro, UFSCar, Campus Sorocaba, Brazil, for the use of the DMA and CP Kelco Brasil S/A for the donation of the pectin.

4. Averous L and Boquillon N. Biocomposites based on plasticized starch: thermal and mechanical behaviours. Carbohydrate Polymers. 2004; 56(2):111-122.

5. Carvalho AJ, Zambon MD, Da Silva CA and Gandini A. Thermoplastic starch modification during melt processing: Hydrolysis catalyzed by carboxylic acids. Carbohydrate Polymers. 2005; 62(4):387-390.

6. Da Roz AL, Carvalho AJ, Gandini A and Curvelo AA. The effect of plasticizers on thermoplastic starch compositions obtained by melt processing. Carbohydrate Polymers. 2006; 63(3):417-424.

7. Da Roz AL, Zambon MD, Curvelo AA and Carvalho AJ. Thermoplastic starch modified during melt processing with 
organic acids: The effect of molar mass on thermal and mechanical properties. Industrial Crops and Products. 2011; 33:152-157.

8. Teixeira ED and Da Roz AL. Carvalho AJCurvelo AA Preparation and characterisation of thermoplastic starches from cassava starch, cassava root and cassava bagasse. Macromolecular Symposia. 2005; 229(1):266-275.

9. Yu JG, Wang N and Ma XF. The effects of citric acid on the properties of thermoplastic starch plasticized by glycerol. Stärke. 2004; 57(10):494-504.

10. Xie FW, Yu L, Liu HS and Chen L. Starch modification using reactive extrusion. Stärke. 2006; 58(3-4):131-139.

11. Ayouba A, Berzin F, Tighzert L and Bliard C. Study of the thermoplastic wheat starch cationisation reaction under molten condition. Stärke. 2004; 56(11):513-519.

12. Jin T, Liu LS, Zhang H and Hicks K. Antimicrobial activity of nisin incorporated in pectin and polylactic acid composite films against Listeria monocytogenes. International Journal of Food Science \& Technology. 2009; 44(2):322-329.

13. Mighori M, Gabriele D, Checchetti A, Facciolo D and Battipede B. Effect of water addition on pectin recovery from solution in centrifugal separation process. International Journal of Food Science \& Technology. 2011; 46(1):116-121.

14. Voragen AG, Pilnik W, Thibault J-F, Axelos MA and Renard CM. Pectin. In: Stephen AM, Glyn OP. Food polysaccharides and their applications. New York: Marcel Dekker; 1995. p. 287-340.

15. Piazza L, Duerr-Auster N, Gigli J, Windhab EJ and Fischer P. Interfacial rheology of soy proteins - High methoxyl pectin films. Food Hydrocolloids. 2009; 23(8):2125-2131.

16. Coffin DR and Fishman ML. Physical and mechanical properties of highly plasticized pectin/starch films. Journal of Applied Polymer Science. 1994; 54:1311-1320.

17. Coffin DR and Fishman ML. Viscoelasticity properties of pectin/ starch blends. Journal of Agricultural and Food Chemistry. 1993; 41:1192-1197.

18. Fishman ML, Coffin DR, Onwukata CI and Konstance RP. Extrusion of pectin and glycerol with various combinations of orange albedo and starch. Carbohydrate Polymers. 2004; 57(4):401-413.

19. Fishman ML, Coffin DR, Unruh JJ and Ly T. Pectin/starch/ glycerol films: lends or composites? Journal of Macromolecular science. Pure and Applied Chemistry. 1996; A33:639-654.

20. Fishman ML, Walker PN, Chau HK and Hotchkiss AT. Flash extraction of pectin from orange albedo by steam injection. Biomacromolecules. 2003; 4(4):880-889.

21. Lenart A and Dabrowska R. Kinetics of osmotic dehydration of apples with pectin coatings. Drying Technology: An International Journal. 1999; 17(7-8):1359-1373. http://dx.doi. org/10.1080/07373939908917620.
22. Rutiaga MO, Galan LJ, Morales LH, Gordon SH, Imam SH, Orts WJ, et al. Mechanical property and biodegradability of cast films prepared from blends of oppositely charged biopolymers. Journal of Polymers and the Environment. 2005; 13(2):185-191.

23. Taggart TE, Schuster A and Schellhamer AJ. Papermaking using cationic starch and naturally anionic polysaccharide. US Patent US5104487. 1992 Abril 14.

24. Prado HJ and Matulewicz MC. Cationization of polysaccharides: A path to greener derivatives with many industrial applications. European Polymer Journal. 2014; 52:53-75.

25. Prado HJ, Matulewicz MC, Bonelli P and Cukierman AL. Cationization of polysaccharides: A path to greener derivatives with many industrial applications. European Journal of Pharmaceutics and Biopharmaceutics. 2008; 70(1):171-178.

26. Miranda VR and Carvalho AJ. Compatible blends of thermoplastic starch and low density polyethylene compatibilized with citric acid. Polimeros-Ciencia e Tecnologia. 2011; 21(5):353-360. http://dx.doi.org/10.1590/S0104-14282011005000067.

27. Olivato JB, Grossmann MV, Yamashita F, Eiras D and Pessan LA. Citric acid and maleic anhydride as compatibilizers in starch/poly(butylene adipate-co-terephthalate) blends by one-step reactive extrusion. Carbohydrate Polymers. 2012; 87:2614-2618.

28. Raquez JM, Narayan R and Dubois P. Recent advances in reactive extrusion processing of biodegradable polymer-based compositions. Macromolecular Materials and Engineering. 2008; 293:447-470.

29. Raquez J-M, Nabar Y, Srinivasan M, Shin B-Y, Narayan R and Dubois P. Maleated thermoplastic starch by reactive extrusion. Carbohydrate Polymers. 2008; 74(2):159-169.

30. Belitz HD, Grosch W and Schieberle PS. Food chemistry. 3rd ed. Berlim: Springer; 2004.

31. Da Roz AL, Ferreira AM, Yamaji FM and Carvalho AJ. Compatible blends of thermoplastic starch and hydrolyzed ethylene-vinyl acetate copolymers. Carbohydrate Polymers. 2012; 90(1):34-40.

32. Sankri A, Arhaliass A, Dez I, Gaumont AC, Grohens Y, Lourdin $\mathrm{D}$, et al. Thermoplastic starch plasticized by an ionic liquid. Carbohydrate Polymers. 2010; 82(2):256-263.

33. Shi R, Zhang ZZ, Liu QY, Han YM, Zhang LQ, Chen $\mathrm{DF}$, et al. Characterization of citric acid/glycerol co-plasticized thermoplastic starch prepared by melt blending. Carbohydrate Polymers. 2007; 69(4):748-755. http://dx.doi.org/10.1016/j. carbopol.2007.02.010.

34. Gnanasambandam R and Proctor A. Determination of pectin degree of esterification by diffuse reflectance Fourier transform infrared spectroscopy. Food Chemistry. 2000; 68(3):327-332.

35. Einhorn-Stoll U, Benthin A, Zimathies A, Görke O and Drusch S. Pectin-water interactions: Comparison of different analytical methods and influence of storage. Food Hydrocolloids. 2015; 43:577-583. 